\title{
Exploring Vascular Function Biomarkers: Implications for Rehabilitation
}

\author{
Shane A. Phillips¹, PhD; Daniela Kuguimoto Andaku², PhD; Renata Gonçalves Mendes², PhD; Flávia Rossi Caruso², \\ PhD; Ramona Cabiddu², PhD; Rodrigo Boemo Jaenisch², PhD; Ross Arena' ${ }^{1}$ PhD; Audrey Borghi-Silva², PhD
}

DOI: 10.21470/1678-9741-2016-0085

\section{Abstract}

The endothelium plays an important role in maintaining vascular homeostasis and regulating blood vessel function. Endothelial function is considered an independent predictor for risk of future cardiovascular events in cardiovascular and noncardiovascular patients, as well as a predictor for postoperative complications in cardiovascular surgery patients. Brachial artery flow-mediated dilation by high-resolution ultrasound is widely used to evaluate endothelium-dependent vasodilation, which is mainly mediated by nitric oxide release. Physical exercise exerts beneficial effects on endothelial function and can be used in both primary and secondary prevention of cardiac and peripheral artery diseases, even in the postoperative period of cardiovascular surgery.

Keywords: Rehabilitation. Atherosclerosis. Endothelium.

\begin{tabular}{|c|c|c|c|}
\hline \multicolumn{4}{|c|}{ Abbreviations, acronyms \& symbols } \\
\hline CAD & $=$ Coronary artery disease & HIAE & $=$ High intensity interval aerobic exercise \\
\hline CAE & $=$ Continuous moderate intensity aerobic exercise & IMT & $=$ Intima-media thickness \\
\hline CHS & $=$ Cardiovascular Health Study & LVEF & $=$ Left ventricular ejection fraction \\
\hline CV & $=$ Cardiovascular & MI & $=$ Myocardial infarction \\
\hline CVD & $=$ Cardiovascular disease & NADH & $=$ Nicotinamide adenine dinucleotide \\
\hline CPB & $=$ Cardiopulmonary bypass & NADPH & $=$ Nicotinamide adenine dinucleotide phosphate \\
\hline CR & $=$ Cardiac rehabilitation & NO & $=$ Nitric oxide \\
\hline EDCF & $=$ Endothelium-derived contracting factors & $\mathrm{OH} \cdot$ & $=$ Hydroxyl radicals \\
\hline EDHF & = Endothelium-derived hyperpolarizing factor & PAD & $=$ Peripheral arterial disease \\
\hline EDRF & $=$ Endothelium-derived relaxing factors & $\mathrm{PCl}$ & $=$ Percutaneous coronary intervention \\
\hline EDV & = Endothelium-dependent vasomotion & $\mathrm{PGl}_{2}$ & $=$ Prostaglandin $\mathrm{I}_{2}$ \\
\hline eNOS & $=$ Endothelial NO synthase & ROS & $=$ Reactive oxygen species \\
\hline ET-1 & = Endothelin-1 & SOD & $=$ Superoxide dismutase \\
\hline FMD & = Flow-mediated dilation & uAP & $=$ Unstable angina pectoris \\
\hline GPx & $=$ Glutathione peroxidase & VEGF & $=$ Vascular endothelial growth factor \\
\hline $\mathrm{H}_{2} \mathrm{O}_{2}$ & = Hydrogen peroxide & VTI & $=$ Velocity time integral \\
\hline
\end{tabular}

'Department of Physical Therapy, Integrative Physiology Laboratory, College of

Applied Health Sciences, University of Illinois at Chicago, Chicago, IL, USA.

${ }^{2}$ Cardiopulmonary Physiotherapy Laboratory, Department of Physiotherapy,

Universidade Federal de São Carlos (UFSCAR), São Carlos, SP, Brazil.

This study was carried out at the Department of Physical Therapy, Integrative

Physiology Laboratory, College of Applied Health Sciences, University of Illinois at Chicago, Chicago, IL, USA.

No financial support.
No conflict of interest.

Correspondence Address:

Audrey Borghi-Silva

Universidade Federal de São Carlos - Physical Therapy

Rod. Washington Luiz, km 235 - São Carlos, SP, Brazil - Zip code: 13565-905

E-mail: audrey@ufscar.br 


\section{INTRODUCTION}

\section{The Role of the Endothelium in Regulating Vascular Health}

The endothelium is the first line of defense of endorgans against external aggression and plays an important role in maintaining vascular homeostasis ${ }^{[1]}$. Endothelial cells control vascular function by responding to various hormones, neurotransmitters and vasoactive factors which affect vasomotion, thrombosis, platelet aggregation and inflammation ${ }^{[2]}$. The endothelium mediates the vasomotor tone of the circulation in response to various chemical (acetylcholine, ACh) or physical (shear stress) stimuli[3], by synthesizing and releasing different vasodilator and vasoconstrictor mediators. There are endothelium-derived relaxing factors (EDRF), including nitric oxide (NO), prostaglandin $\mathrm{I}_{2}\left(\mathrm{PGI}_{2}\right)$, and endotheliumderived hyperpolarizing factor (EDHF), but also endotheliumderived contracting factors (EDCF), including endothelin-1 (ET-1) representing the most potent molecule.

\section{Mechanisms of Vasodilator Function}

NO has been shown to play an important role in the maintenance of basal vasodilator tone of the blood vessels and plays a key role in vasodilation ${ }^{[4]}$. It also prevents platelet adhesion and aggregation, as well as leukocyte adhesion and migration into the arterial wall and inhibits smooth muscle cell proliferation and intimal migration, oxidation of LDL cholesterol, apoptosis of smooth muscle cells, all key events in the development of atherosclerosis ${ }^{[2]}$.

\section{Mechanism of Flow-Mediated Vasodilation}

Flow-mediated dilation (FMD) is a physiologically important stimulus regulating vascular tone and homeostasis of the peripheral circulation. This important endothelial mechanism of vasodilation occurs in virtually every vascular bed. In large arteries, FMD may be critical for preventing atherosclerosis through release NO. In humans, a reduction in FMD is prognostic of cardiovascular disease (CVD). Animal studies have reported that the contribution of NO to FMD is reduced as oxidative stress increases in the presence of risk factors for CVD ${ }^{[5]}$. In humans, in vivo and in vitro studies have demonstrated that relaxant factor(s), other than $\mathrm{NO}$, compensate to maintain FMD when NO availability is reduced ${ }^{[6]}$. Altered endotheliumdependent FMD is a hallmark of the development of CVD and is an initiating event in the development of atherosclerotic heart disease $\mathrm{e}^{[7]}$. During coronary artery disease (CAD), arterioles exhibit altered endothelium-dependent vasodilation ${ }^{[8]}$. In humans, Phillips et al. ${ }^{[6]}$ have shown that hydrogen peroxide $\left(\mathrm{H}_{2} \mathrm{O}_{2}\right)$ replaces $\mathrm{NO}$ as the mediator of endothelium-dependent flow-induced dilation in resistance arteries of visceral fat in the presence of CAD. An increase in oxidative stress appears to be a major mechanism underlying the development of vascular endothelial dysfunction. The dominant mechanism responsible for endothelial dysfunction is the decrease in bioavailable NO, as well as the increase in reactive oxygen species (ROS) production. The generation of ROS in the endothelium includes anions
$\left(\mathrm{O}_{2}\right)$, hydroxyl radicals $(\mathrm{OH})$ and hydrogen peroxide $\left(\mathrm{H}_{2} \mathrm{O}_{2}\right)$. ROS modulate vascular tone by several mechanisms; directly act as EDCF or indirectly potentiate EDCF mediated responses by reducing the bioavailability of NO. ROS might interact with $\mathrm{NO}$ and reduce its bioavailability via different pathways: direct $\mathrm{NO}$ inactivation by superoxide with peroxynitrite (ONOO-) formation; reduction in NO synthase expression and activity due to changes in their substrate or cofactors, and also endothelial NOS uncoupling ${ }^{[9]}$.

\section{Methods in Evaluating Peripheral Vascular Function Rationale for Measuring Peripheral Arterial Function}

The endothelium occupies a unique position in that it is able to secrete a variety of vasoactive molecules and is also exposed to direct vascular injury. It is thus an important mediator of atherosclerosis formation and is widely perceived to be a metric of vascular risk. Previous studies have demonstrated a correlation between measures of coronary vasodilator function and FMD ${ }^{[10]}$. Early studies established that attenuated vascular responses occur prior to the development of atherosclerosis in response to a milieu of risk factors, thus making measurements attractive as a screening tool for cardiovascular (CV) risk ${ }^{[7]}$. Endothelial function is dynamic and can be attenuated rapidly in response to acute oxidative stress (cigarette smoking, high fat load). In addition, interventions that are associated with a decrease in vascular risk will improve vasodilation within a period of months allowing one to determine the impact of novel interventions in a timely fashion ${ }^{[1]}$.

\section{Non-invasive Conduit Vessel Endothelial Function Brachial artery FMD}

Celermajer et al. ${ }^{[12]}$ showed the first report of the measurement of peripheral artery FMD in 1992. Not only were they able to describe a new method, but also demonstrated that children with familial hypercholesterolemia had impaired function at an early age. Since then thousands of studies have been reported using this methodology. The guidelines for measuring brachial artery FMD are summarized previously ${ }^{[3]}$. Briefly, a high resolution (> $10 \mathrm{MHz}$ ) linear array ultrasound probe is used to longitudinally image the brachial (or radial) artery at rest. A thin blood pressure (BP) cuff is inflated to suprasystolic pressure for 5 minutes on either the forearm or on the upper arm. After the cuff is released, the artery dilates in response to shear stress mediated $\mathrm{NO}$ release and maximum dilation typically occurs between 45 and 120 seconds ${ }^{[13]}$. After a 5 minutes recovery period, sublingual nitroglycerine may be given to assess endothelium-independent dilation. The FMD response has been shown to be mediated mainly by $\mathrm{NO}$, thus it reflects endothelium-dependent vasodilation [14]. Two large cohort studies, the Cardiovascular Health Study $(\mathrm{CHS})^{[15]}$ and the Multi-ethnic Study of Atherosclerosis ${ }^{[16]}$, demonstrated that FMD was an independent predictor of CV outcomes. FMD remains the standard tool for research studies designed understand the effects of novel risk factors or treatments on peripheral artery conduit vessel function. Main recommendations for brachial artery flow-mediated dilation measurement are in Table 1. 
Table 1. Recommendations for brachial artery flow-mediated dilation measurement.

\author{
Patient instructions \\ Fasting for at least 6 hours \\ No vasoactive medications for $>12$ hours \\ No caffeine, cigarettes or nicotine for $>12$ hours \\ No physical exercise for $>6$ hours \\ Pre-menopausal women studied on day 1-7 of menstrual cycle
}

\title{
Pre data acquisition
}

Rest in supine position for at least 20 minutes (quiet and temperature-controlled room)

Blood pressure cuff positioned on forearm or upper arm

Brachial artery anatomical landmarks identification for serial studies

Linear array Doppler ultrasound machine $>7.5 \mathrm{MHz}$

\section{Data acquisition}

Ultrasound probe is positioned above the antecubital fossa in the longitudinal plane

Optimize image quality with clear identification of lumen interface

Insonation angle $\leq 60$

Baseline recording of diameter and velocity for 1 minute pre cuff inflation

Cuff inflation for 5 minutes at $\geq 50 \mathrm{mmHg}$ above systolic pressure

Record post-cuff release diameter and hyperemia for 3 minutes

Adapted from Anderson \& Phillips ${ }^{[3]}$.

\section{Microvascular Function}

Regional blood flow is in large part controlled by tone in the smaller resistance vessels. Dysfunction of these vessels can lead to ischemia, particularly in the coronary circulation, as is the case in no-reflow or in chest pain syndromes and minimal CAD, syndrome $X$ or microvascular angina.

\section{Venous Occlusion Plethysmography}

Prior to the introduction of the FMD technique, several groups reported on the assessment of changes in forearm blood flow in response to the infusion of intra-arterial vasoactive medications ${ }^{[17]}$. Plethysmography has been a technique to measure blood flow for more than 100 years and is based on the premise of measuring tissue (mainly muscle) blood flow reflected as a change in tissue volume. The standard approach is to use a calibrated mercury-in-silastic strain gauge placed around the forearm ${ }^{[18]}$. A BP cuff is used to isolate the hand and a proximal cuff is inflated to $40 \mathrm{mmHg}$ to prevent venous outflow. Arterial inflow then results in expansion of the forearm with automated calibrated systems allowing the calculation of forearm blood flow in $\mathrm{mL} / \mathrm{min} / 100 \mathrm{~mL}$ tissue. Measurements are generally taken at rest and then after serial direct intra-brachial infusions of escalating doses of endothelium-dependent and independent agonists; Ach (or methacholine) and sodium nitroprusside have been most commonly used. The contralateral arm is used as a control in most laboratories. This provides important information about mechanisms responsible for attenuated responses seen with CV risk factors. Most CV risk factors have attenuated microvascular endothelial function ${ }^{[19]}$. Enzymatic inhibitors or receptor antagonists such as NO synthase inhibitors or adrenergic blockers can also be utilized.

\section{Reactive Hyperemia}

Assessment of FMD typically involves the induction of a shear stress stimulus in the conduit brachial artery following ischemia induced by occlusion of the forearm vessels for 5 minutes. This shear stress is generated by dilation of the microvasculature, thereby producing increased velocity and flow (reactive hyperemia) in the conduit vessel. This can be measured by Doppler ultrasound after the release of the BP cuff and expressed as either peak velocity, the velocity time integral (VTI), forearm blood flow or systolic/diastolic ratio. Huang et al. ${ }^{[20]}$ demonstrated that hyperemic velocity was related to adverse events in subjects with peripheral vascular disease undergoing vascular surgery.

\section{Arterial Biopsy and Isolated Resistance Vessel Function}

Microvascular dysfunction is an important contributor to increased cardiometabolic risk. For example, impaired microvascular function can contribute to reduced insulin sensitivity, increased total peripheral resistance, and altered nutrient disposal[21]. In this context, studies of the isolated, resistance arteries defined by their internal diameter (50-200 $\mu \mathrm{m})$ can be made by dissecting arterioles from tissue biopsies. These biopsies of the microcirculation have been made in the subcutaneous fat and muscle ${ }^{[22]}$. In addition, this technique to isolate arterioles from subcutaneous and visceral fat ${ }^{[23]}$, coronary arterioles discarded during surgery ${ }^{[8]}$. These preparations can 
involve the wire myograph ${ }^{[24]}$ or the isolated perfused arterial preparation with measurements using a video micrometer or an automated edge detector.

\section{ARTERIAL FUNCTION AND CARDIOVASCULAR DISEASE MA- NAGEMENT}

Although recent studies have played important roles in the diagnosis and prognosis of endothelial assessment in individuals with $C A D$, there are several measures which are able to evaluate the endothelial function (EF; see above $)^{[3]}$. In this context, Chan et al. ${ }^{[25]}$, in 2003 evaluated EF by FMD and endotheliumindependent dilations with $0.3 \mathrm{mg}$ sublingually of nitroglycerin (NTG), in 152 CAD subjects. The results demonstrated that FMD and the FMD/NTG ratio were lower in subjects with cardiac events. This result supports the concept that both structural and functional properties of the vasculature are key co-determinants of CVD outcomes. In addition, the authors concluded that the assessment of EF is a predictor of future events, furthermore, the preserved carotid artery structure can mitigate the risk of future events related platelet formation, and the endothelial dysfunction reflects the propensity for atherosclerosis development in response to previous, longstanding exposure to risk factors.

In a recent study, Sugamata et al. ${ }^{[26]}$ assessed the EF in 923 CAD subjects, and were prospectively followed up for $<8.5$ years or until a coronary event - cardiac death, non-fatal myocardial infarction (MI) or unstable angina pectoris (UAP) requiring unplanned coronary revascularization. During the follow-up period, 116 events occurred (29 cardiac deaths, 46 non-fatal MIs and 41 cases UAPs). The results showed that FMD was independent predictor of secondary coronary events in patients with CAD. These findings indicate that FMD may contribute to be useful for risk stratification in patients with CAD.

In another study of patients with established CAD, Simova \& Denchev ${ }^{[27]}$ showed similar results when evaluated in 198 subjects admitted to a hospital with angina and multiple risk factors divided into five groups according to the degree of CAD development. All patients had FMD and intima-media thickness (IMT) measured, 105 (53.03\%) performed a treadmill test, and $146(73.7 \%)$ underwent coronary arteriography (CAG). The results demonstrated that the patients with significant $(\geq 50 \%)$ coronary artery stenosis had lower FMD and higher IMT values compared to patients without significant CAD. They concluded that endothelial evaluation presented important acceptance prognostic in CAD patients.

Furthermore, Kuvin et al. ${ }^{[28]}$, in 2001 evaluated endotheliumdependent vasomotion (EDV) with FMD as a predictor of the presence or absence of CAD as defined by exercise myocardial perfusion imaging (ExMPI) in 94 CAD subjects. The results demonstrated that subjects with $C A D(n=23)$ had a lower FMD (6.3 $\pm 0.7 \%)$ than those without CAD (10.5 $\pm 0.6 \%)$. It was concluded that endothelial evaluation is highly sensitive for coronary disease.

Nevertheless, studies demonstrating the FMD technique in other CV diseases may indicate the diagnosis and prognosis role of this technique. Thereby, Wang et al. ${ }^{[29]}$ in 2009 in a follow-up, assessed the EF by FMD in 101 patients with acute MI and ST- segment elevation. The authors concluded that endothelial dysfunction significantly increased the risk of vascular events against to abnormal EF as a sensitive indicator of early development of atherosclerosis. In the same line of evidence, in 2010 Kaźmierski et al. ${ }^{[30]}$ evaluated 75 men under 45 years of age, who were awaiting for elective coronary angiography in the hospital. The subjects were divided into two groups: study group $(n=55)$ with obstructive coronary lesions and the control group $(n=20)$ without lesions. The authors demonstrated a significant reduction of FMD for the study group when compared to control group (3.92 \pm 1.1 vs. $6.51 \pm 1.1)$. In this context, this finding demonstrated the relationship between the FMD and CV risk factors, estimating which risk factors have significant influence on EF. Additionally, these same authors investigated whether the assessment of EF by FMD can be useful for assessing the risk of CV disease in peri-menopausal women. The study involved 65 women with chest pain divided into a study group (coronary lesions, $n=32$ ) and a control group (without lesions, $n=33$ ). Atherosclerotic risk factors, early atherosclerotic remodeling by IMT and endothelial dysfunction measured by FMD were analyzed in all subjects. The results showed that IMT was significantly higher in the study group compared with controls $(0.059 \pm 0.01$ vs. $0.049 \pm 0.01 \mathrm{~mm})$, moreover the FMD was significantly lower in the study group compared with controls (6.53 \pm 0.98 vs. $7.89 \pm 0.85)$. However, these results can be influenced by the presence of hypercholesterolemia and all components of the metabolic syndrome as well as by pharmacotherapy of these risk factors. The authors concluded that FMD can be an important diagnostic tool to assess CV risk ${ }^{[31]}$.

Therefore, in this context, in a meta-analysis by Inaba et al. ${ }^{[32]}$, FMD is closely related to the future of CV events, but further studies are needed to confirm the effectiveness of the use of FMD in CV disease management. In this sense, a study by Patti et al. ${ }^{[33]}$, evaluated the recurrence of stenosis in 136 patients with singlevessel CAD undergoing percutaneous coronary intervention (PCl) with stenting and at least 6 months of follow-up. All patients underwent FMD 30 days after PCl; and nitroglycerin-FMD were investigated before and after administration of sublingual NTG. The results showed that clinical in-stent restenosis was demonstrated in 20 (15\%) patients, whereas 116 (85\%) patients remained free of signs or symptoms of recurrent ischemia. Also, FMD was significantly impaired in patients with restenosis versus those without restenosis. The authors concluded that early evaluation of endothelial assessment may represent an important tool for predicting CV risk futures.

On the other hand, Frick et al. ${ }^{[34]}$ in 2005, assessed the prognostic value of FMD in a follow-up of 398 patients admitted to hospital with chest pain. Patients were divided into two groups according to the FMD median (7.6\%), and after a mean follow-up of $39 \pm 12$ months, CV events were documented. The results of the study demonstrated no difference in the number of CV events between groups. The authors concluded that IMT predicted late (up to 4 years) CV events, while the FMD technique is an important prognostic tool for CV event predictor.

Muiesan et al. ${ }^{[35]}$ evaluated 172 hypertension patients with the objective to evaluate the incidence of CV events during follow-up an evaluation of EF in the brachial artery. The results demonstrated that the CV events occurred in fewer patients with 
preserved FMD than in those with impaired FMD 23 (27\%) vs. 9 (10.5\%), with an incidence of 1.4 and 3.1 CV events per 100 patient-years. They concluded that uncomplicated hypertensive patients, followed up for an average period of 8 years, endothelial dysfunction, might identify patients at higher risk of CV events.

Considering others CV diseases, Meyer et al. ${ }^{[36]}$ assessed 75 CHF patients with a left ventricular ejection fraction (LVEF) $\leq 30 \%$, which aimed to evaluate the predictive potency of impaired endothelium dependent in this population. The results showed that FMD significantly differed between event-free survivors or death in 75 CHF patients with LVEF $\leq 30 \%$, FMD values were significantly impaired in CHF patients who reached the combined endpoint as compared with CHF survivors $(5.4 \pm 5.1 \%$ vs. 11.2 $\pm 7.4 \%)$. These finding may be the result of the impact of reduced $\mathrm{EF}$ in CHF. Therefore, reduced FMD may be an important tool for the composite physiological and prognostic assessment of patients with $\mathrm{CHF}$.

\section{IMPACT OF EXERCISE PRESCRIPTION ON ARTERIAL FUNCTION}

Physical exercise exerts beneficial effects on the human vascular system. Its acute and chronic impact has been targeted by many investigators over time ${ }^{[9,37]}$. The mechanism by which exercise results in improvement of arterial health is complex and is not fully understood. However, the effects of exercise on arterial function may be in part related to improvements in the endothelium function and health status.

Evidence suggests that exercise induces an up-regulation of endothelial NO synthase (eNOS) gene expression and vascular endothelial growth factor (VEGF)-induced angiogenesis; it also leads to a decrease in $\mathrm{NO}$ inactivation with augmented availability of antioxidants, such as superoxide dismutase (SOD) and glutathione peroxidase (GPx), and to an attenuation of nicotinamide adenine dinucleotide/nicotinamide adenine dinucleotide phosphate (NADH/NADPH) oxidase activity, leading to an increase in NO bioavailability ${ }^{[9,37,38]}$.

The shear stress effect on eNOS expression after exercise training was experimentally observed in animal models and in human studies ${ }^{[39]}$. Hambrecht et al. ${ }^{[40]}$ observed that a 4 weeks regular exercise training induced a 2-fold increase in eNOS mRNA expression and vascular protein content in stable CAD patients, suggesting that endothelial function improved possibly due to augmented eNOS phosphorylation. Maiorana et al. ${ }^{[41]}$, assessed conduit vessel endothelial function in diabetic patients using FMD of the brachial artery and demonstrated that 8 weeks of circuit training did not affect vascular function in healthy men. However, Clarkson et al. ${ }^{[42]}$ observed that FMD was enhanced following a 10 weeks program of daily aerobic and anaerobic exercise training in healthy young men. Other evidence from CAD patients showed that ET increases coronary blood flow through direct actions on the vasculature that improve endothelial function, enhancing coronary vasodilation ${ }^{[43]}$ and that even short-term ET could begin to reverse endothelial dysfunction in these patients, even though a longer duration is needed to restore endothelial function ${ }^{[44]}$.

Siasos et al. ${ }^{[45]}$ investigated the effects of continuous moderate and high intensity interval aerobic exercise on endothelial function and arterial stiffness in healthy subjects and demonstrated that both have favorable effects, suggesting a cardioprotective effect of both intensities of exercise. However, in another study, Franklin et al. ${ }^{[46]}$ showed that acute physical stress induced by resistance exercise reduces FMD in sedentary obese women, suggesting that this response to acute physical exertion may be an important marker for CV risk prediction in this population.

A wealth of studies has been published whose results support the beneficial effects of exercise training on arterial function. Evidence from subjects with endothelial dysfunction confirms that exercise training improves vasodilator function of resistance or conduit arteries ${ }^{[44]}$. However, findings from investigations on healthy asymptomatic subjects with presumably normal endothelial function are less consistent ${ }^{[47]}$. The acute effects of exercise on endothelium have been studied, but the number of studies is scarce and results are controversial. Another important aspect to be considered is that different exercise modalities are associated with different patterns of blood flow and arterial shear stress which may somehow impact on responses and adaptation of arterial function ${ }^{[9]}$. Besides, physiological adaptation may depend on exercise intensity, duration and frequency. Therefore, future studies to investigate the optimum exercise prescription in terms of modes, intensities and volume are needed. Table 2 summarizes the main exercise training programs studies assessing change in FMD CAD patients.

\section{EXERCISE, ARTERIAL FUNCTION AND CARDIAC REHABILITATION}

Exercise-based cardiac rehabilitation (CR) is widely recognized as a non-pharmacological adjunct able to reduce all-cause and cardiac mortality and the incidence of acute cardiac events, to modify risk factors associated with CVD and to mitigate CV disease progression ${ }^{[37]}$. Exercise training positive effects on CV risk exposure are partially due to its direct effects on the vessel wall[48]. Exercise induces increases in blood flow and shear stress, which are recognized as important physiological stimuli for arterial function improvement ${ }^{[37]}$.

Long-term vasculature adaptations determined by physical exercise result in an improvement of systemic arterial vascular function not just in healthy individuals, but also in patients affected by CVD. Arterial health can be compromised in various pathological conditions affecting the cardiovascular system and in the presence of CVD risk factors. Evidence shows that exercise is beneficial for patients suffering from a variety of chronic diseases, including hypertension (HTN), coronary heart disease (CHD), heart failure (HF) (reviewed above), obesity and insulin resistance ${ }^{[9]}$.

Higashi et al. ${ }^{[38]}$ investigated FMD in HTN subjects and showed that moderate intensity aerobic exercise significantly improved endothelial health in this population. Collier et al. ${ }^{[49]}$ showed that arterial function was improved in HTN patients following 4 weeks of either aerobic or resistance training. Most of the studies that investigated ET effects on endothelial function reported correlations with improved insulin sensitivity and other insulin mediated metabolic functions ${ }^{[9]}$. Hambrecht et al. ${ }^{[44]}$ studied the cardioprotective effects of ET in CAD patients and showed that 
Table 2. Summary of exercise training studies assessing change in FMD in coronary arterial disease patients.

\begin{tabular}{|c|c|c|c|c|}
\hline Study & Cohort & Study design & Exercise training & Outcome(s) \\
\hline $\begin{array}{l}\text { Van Craenenbroeck } \\
\text { et al. }{ }^{[60]}\end{array}$ & Stable CAD & $\begin{array}{c}200 \text { CAD randomized into } \\
2 \text { groups }\end{array}$ & $\begin{array}{c}\text { 12-wk of AIT vs. ACT on a bicycle, } \\
3 \text { times a week }\end{array}$ & $\begin{array}{l}\text { Both training changed } \\
\text { FMD\% and peak } \mathrm{VO}_{2}\end{array}$ \\
\hline Kim et al..59] & $\begin{array}{l}\text { Patients who } \\
\text { received PCI due } \\
\text { to ACS }\end{array}$ & $\begin{array}{l}32 \text { nonrandomly divided } \\
\text { into control }(n=16) \text { or } C R \\
(n=16) \text { group }\end{array}$ & $\begin{array}{c}\text { 6-wk of 50-minute ACT, } 3 \text { times } \\
\text { a week }\end{array}$ & $\begin{array}{c}\text { peak } \mathrm{VO}_{2} \text { and } \mathrm{FMD}(\% \\
\text { and change) only for } \\
\text { CR group }\end{array}$ \\
\hline Currie et al.[61] & Stable CAD & $\begin{array}{c}22 \text { CAD patients } \\
\text { randomized into HIT } \\
(n=11) \text { or } A C T(n=11) \\
\text { based on pretraining FMD }\end{array}$ & $\begin{array}{l}\text { 12-wk of ACT (30-50 min of } \\
\text { cycling at 58\%WR vs. HIT ( } 10 \\
\text { 1-min intervals at } 89 \% \text { separated } \\
\text { by 1-min intervals at 10\% WR) }\end{array}$ & $\begin{array}{l}\text { Both training changed } \\
\mathrm{FMD} \% \text { and peak } \mathrm{VO}_{2}\end{array}$ \\
\hline Luk et al. ${ }^{[58]}$ & Stable CAD & $\begin{array}{l}64 \text { randomized into } \\
\text { control ( } 32 \text { ) and exercise } \\
\text { training program }\end{array}$ & 8-wk of ACT program & $\begin{array}{l}\text { FMD (1.84\%) and } \\
\text { exercise capacity ( } 2 \\
\text { METS) only in ACT } \\
\text { group }\end{array}$ \\
\hline Walsh et al. ${ }^{[62]}$ & Stable CAD & $\begin{array}{l}20 \text { CAD patients } \\
\text { randomized in } 2 \text { groups } \\
\text { (trained vs. controls) }\end{array}$ & $\begin{array}{c}8 \text { wk of combined aerobic (70\% } \\
\text { MHR) + resistance circuit training } \\
(55-65 \% \text { MR) }\end{array}$ & $\begin{array}{l}\text { FMD }(\%) \text { and glyceryl } \\
\text { trinitrate GTN- } \\
\text { mediated dilation only } \\
\text { in trained group }\end{array}$ \\
\hline
\end{tabular}

$A C T=$ aerobic continuous training; $A C S=$ acute coronary syndrome; $A I T=$ aerobic interval training; $C A D=$ coronary arterial disease; $\mathrm{CR}=$ cardiac rehabilitation; GTN=glyceryl trinitrate; $\mathrm{HIT}=$ high-intensity training; $\mathrm{MET}=$ metabolic equivalent; $\mathrm{MHR}=$ maximal heart rate; $\mathrm{MR}=$ maximal repetition; $\mathrm{PCl}=$ percutaneous coronary intervention; $\mathrm{VO}_{2}=$ oxygen uptake; $\mathrm{WR}=\mathrm{work}$ rate.

4 weeks of ET on a cycle ergometer improved endotheliumdependent vasodilation both in epicardial coronary vessels and in resistance vessels.

Collectively, evidence suggests that arterial function is amenable to improvement in subjects at known or increased cardiovascular disease risk who undertake physical exercise training. In the sections that follow, we will present existing evidence related to how exercise training can be applied for primary and secondary CVD prevention.

\section{a. Primary Prevention}

Evidence suggests that lifestyle modification via regular exercise has significant preventive effects against CVD by reducing multiple risk factors; on the other hand, physical inactivity is largely associated with CVD development. One of the factors that contribute to the genesis of CVD ${ }^{[37]}$.

Impaired endothelium-dependent vasodilation appears to be the earliest event of atherosclerosis and is therefore considered the focus of strategies for CVD prevention. Moreover, endothelial dysfunction has been extensively associated with most of the established CV risk factors (e.g. dyslipidaemia, hypertension, smoking, and diabetes mellitus). Experimental findings demonstrate that exercise training is able to prevent and improve endothelial dysfunction. Furthermore, management of $\mathrm{CV}$ risk factors also tends to improve or restore endothelial function ${ }^{[9,50]}$.

Jacomini et al. ${ }^{[51]}$ studied the influence of the training status on blood pressure in older women and showed that better performance in a Fitness Battery Test and higher maximal oxygen uptake were related to lower levels of oxidative stress and protein damage. Moreover, the authors observed that a better training status is related to a higher concentration of nitrite and nitrate, a decrease of which was shown to be correlated with increasing numbers of CV risk factors and endothelial dysfunction.

Regular aerobic exercise was also associated with improvements in conduit artery and microvessel FMD, following an acute strenuous physical exertion in overweight and obese individuals. Since acute stress to the vascular endothelium is linked to higher incidence of CVD, physical exercise practice appears to be fundamental to protect against vascular dysfunction ${ }^{[50]}$.

The acute effects of continuous moderate intensity aerobic exercise (CAE) and high intensity interval aerobic exercise (HIAE) on endothelial function and arterial stiffness were investigated by Siasos et al. ${ }^{[45]}$ in healthy individuals. Participants performed an isocaloric protocol on a cycle ergometer and presented significantly improved FMD after both protocols. The authors suggested a cardioprotective effect of exercise on the progression of atherosclerosis.

\section{b. Secondary Prevention}

It is clearly recognized that physical inactivity is related to increased risk for morbidity and mortality and contributes to health care costs, particularly in patients with CVD ${ }^{[52]}$. Therefore, Schmidt et al. ${ }^{[53]}$ have recently focused on evaluating the mechanisms responsible for the systemic effects of physical exercise on secondary CV prevention. 
The potential beneficial effects of exercise are multifaceted. In the context of vascular function, physical exercise induces upregulation of eNOS expression and activity, which has been associated to consequent endothelium-dependent vasodilatation ${ }^{[54]}$. This phenomenon is linked to consequent peripheral neovascularization including arterial function and angiogenesis. In addition, the vascular system is expanded in size and number of microvessels in patients with $C A D^{[55]}$.

Attention has focused on noninvasive tools to measure of arterial function in CAD patients. Based on the ability of the endothelium to acutely dilate in response to an increase in blood flow, the FMD has been constituted as an important index of endothelial function predictive of future CV events in chronic arterial disease ${ }^{[56]}$. In addition, impaired endothelial function has been shown to limit exercise performance in CAD patients ${ }^{[57]}$, even as a lower level of habitual PAL is associated with impaired FMD in these patients ${ }^{[58]}$. FMD also have demonstrated to be a reproducible measurement for short- and medium-term assessment of pharmacological and nonpharmacological interventions, such as exercise training. However, different modalities of physical training program, training intensity duration, as well as volume of exercise training, can influence on endothelial function responses in coronary disease patients.

For instance, Kin et al. ${ }^{[59]}$ applied a protocol based on six-week and three times a week of aerobic exercise training program in a group of patients who were hospitalized due to acute coronary syndrome. The intensity of exercise training program consisted of $40 \%-85 \%$ of the heart rate reserve and the total duration were 30 minutes, intercalating rest periods with exercise on a cycle and treadmill. They observed a significant improvement of FMD change after 6 weeks, however, a none significant difference was observed when compared to controls. However, 12 weeks of both aerobic interval training and continuous exercise training on cycle could significantly improve aerobic capacity (as expressed by $\mathrm{VO}_{2}$ peak), markers of endothelial integrity and FMD percentage in a large population of CAD patients ${ }^{[60]}$.

On the other hand, Currie et al. ${ }^{[6]]}$ contrasted 12 week of lowvolume high-intensity interval exercise training versus higher volume, moderate intensity endurance exercise. Both training program significantly increased relative FMD post training in a similar way, with no differences between groups. These results taken together show that longer protocols (12 weeks) seem to demonstrate better responses, and that, in addition, continuous or interval training may be both important training strategies to improve endothelial function in patients with CAD. In addition, Walsh et al. ${ }^{[62]}$ tested the effects of resistance associated to aerobic exercise training program was applied during 8 weeks, three times a week. The authors observed that combined exercise training improved FMD percentage, but not the responsiveness of endothelium-independent vasodilation, measured by administration of glyceryl trinitrate.

Although there is already a certain body of knowledge about the potential beneficial effects of physical exercise on endothelial function in patients with CAD, there is still a need for future studies to evaluate long-term effects of physical training in these patients. In addition, there is still no evidence for the effects of high versus low continuous intensity training, as well as the effects of resistance training and strength training in these patients. Thus, new studies in order to evaluate these existing gaps still become necessary in future studies.

\section{c. Peripheral Arterial Disease}

Peripheral arterial disease (PAD) affects eight million men and women in the USA, however, in Brazil, data related to the prevalence of PAD and its risk factors are scarce and restricted to specific populations. Endothelial function is impaired in individuals with PAD compared to individuals without PAD ${ }^{[63]}$. On the other hand, higher levels of physical activity during daily life are associated significantly and independently with better brachial artery FMD among individuals with PAD.

In this context, Januszek et al.[64] showed that 12 weeks of supervised, intermittent treadmill walking until induce claudication, three times a week, prolonged the asymptomatic walking distance and improved brachial artery FMD in 43\% after program. Another study that tested the hypothesis of potential effects of endothelial function in PAD patients that underwent to a supervised treadmill training program of 12 weeks found that brachial artery FMD values increased by $45 \%$ after program and the patients with better walking abilities at baseline derived greater clinical and metabolic benefits ${ }^{[6]}$. However, a recent meta-analysis study observed that exercise training, compared with medical care, significantly improved cardiorespiratory fitness, pain-free and total flat-ground walking distances, as well as graded treadmill performance in PAD, but not ankle-brachial index and FMD in PAD patients ${ }^{[66]}$.

In conclusion, to date, the effects of resistance and strength training on FMD in PAD patients. New studies with the objective of testing the potential effects of resistance exercise protocols can be conducted in the future.

\section{ARTERIAL FUNCTION, REHABILITATION AND STROKE}

Considering that endothelial dysfunction plays a role in the development and progression of atherosclerosis, ischemic stroke is also strongly associated with endothelial dysfunction. In fact, patients with acute ischemic stroke have impaired FMD in comparison with control subjects, FMD is negatively related to stroke severity, and impaired FMD is also associated with poor outcome in these patients ${ }^{[67]}$. In addition, $\mathrm{FMD} \leq 4.5 \%$ was an independent predictor of a new-onset vascular event after stroke, with lower event-free survival rates within 48 months after a first ischemic stroke ${ }^{[68]}$.

It is well established that physical activity, as a modifiable risk factor, has beneficial effects on cardiovascular health ${ }^{[37]}$. Improvement on endothelial function and neovascularization related to regular exercise training contribute to these results, therefore, it is reasonable to predict the importance of exercise on prevention of cerebrovascular disease ${ }^{[53]}$. The Cardiovascular Health Study found that greater levels of physical activity were associated to lower incidence of stroke in a population of 4207 US men and women with age $\geq 65$ years followed for 10 years ${ }^{[6]}$. The Women's Health Study also demonstrated that leisure time physical activity was associated to lower stroke risk in healthy women $\geq 45$ years followed for 11.9 years, in average ${ }^{[70]}$. 
There are few studies related to endothelial function after rehabilitation in stroke patients. Billinger et al. ${ }^{[71]}$ applied 8 weeks of aerobic exercise three times per week in 9 subacute stroke patients. They evaluated brachial artery FMD in both arms (stroke-affected and non-affected limbs) at baseline, postintervention and 1 month follow-up. The authors found lower FMD in the affected arm at baseline and at post-intervention measurements, with improvement on vascular health after treatment with sustained improvement on follow-up. Takatori et al. ${ }^{[72]}$ performed a randomized controlled study investigating the effects of intensive rehabilitation for 12 weeks, twice a week, on physical and arterial function of chronic stroke survivors patients. The authors found a significant improvement on arterial function (cardio-ankle vascular index and ankle-brachial pressure index) after the rehabilitation period on experimental group in comparison with control group, despite of no changes on physical function.

\section{ARTERIAL FUNCTION AND CARDIOVASCULAR SURGERY}

The diagnostic value of microvascular and conduit artery endothelial dysfunction has increasingly been investigated in the cardiovascular population ${ }^{[73]}$. Flow-mediated dilation, quantified by noninvasive methods such as brachial artery reactivity testing (BART), is impaired in patients with $C A D^{[73]}$, providing improved sensitivity and negative predictive value for the diagnosis of CAD. Cardiovascular risk factors predispose to perioperative morbidity and mortality, with evidence that patients with microvascular dysfunction undergoing cardiovascular interventions are at increased risk for postoperative complications ${ }^{[73]}$.

In this context, Patti et al. ${ }^{[33]}$ included in a prospective study 136 patients with single-vessel CAD undergoing percutaneous coronary intervention $(\mathrm{PCl})$ with stenting and at least 6 months of follow-up. The authors verified whether early measurement of brachial artery FMD after coronary stenting could predict occurrence of in-stent restenosis. All patients underwent ultrasound detection of brachial artery reactivity 30 days after $\mathrm{PCl}$. FMD was significantly impaired in patients with restenosis versus those without restenosis (percent diameter variation $4.6 \pm 5.8 \%$ versus $9.5 \pm 6.6 \%, P=0.002)$; moreover, $4 \%$ of patients with FMD $\geq 7 \%$ (median value) developed in-stent restenosis versus $28 \%$ of those with $\mathrm{FMD}<7 \%(P=0.0001)$. The results this study indicating that impaired FMD independently predicts occurrence of instent restenosis in patients undergoing $\mathrm{PCl}$ and may represent a useful screening tool to stratify patients according to future risk of restenosis.

Cardiopulmonary bypass (CPB) exerts several deleterious effects in patients undergoing myocardial revascularization, including inflammatory pathways. Most of these can be related to an endothelial insult leading to endothelial dysfunction. Sangalli et al. ${ }^{[74]}$ using FMD of the brachial artery assessed 29 patients undergoing elective myocardial revascularization. Ten patients receiving continuous-flow $C P B, 10$ receiving pulsatileflow CPB, and 9 scheduled for beating-heart revascularization were studied. Patients were studied at baseline (after induction of general anesthesia), after CPB upon intensive care unit (ICU) admission after surgery, and on the first postoperative day before discharge from the ICU (on average, 24 hours after CPB discontinuation). The continuous-flow CPB group demonstrated a significant reduction in FMD after CPB $(12.8 \pm 9.7 \%$ vs. $1.6 \pm 1.5 \%, P<0.01)$, which lasted up to the first postoperative day $(5.9 \% \pm 4.1 \%)$. On the other hand, FMD did not change in the pulsatile-flow group $(12.5 \pm 10.5 \%, 11.0 \pm 7.2 \%$, and $16.6 \pm 11.7 \%$, respectively). FMD also was unaffected in the beating-heart group, thus suggesting a direct effect of CPB itself on endothelial function. In conclusion, in these patients, continuous-flow CPB markedly impaired endothelial function, although this was not the case with pulsatile-flow CPB group.

Gokce et al. ${ }^{[75]}$ preoperatively examined brachial artery vasodilation using ultrasound in 187 patients undergoing a vascular operation, including carotid endarterectomy (47 patients), femoral-popliteal or other peripheral bypass (100 patients), aortic aneurysm repair (24 patients), and limb amputation (16 patients). Patients were prospectively followed for 30 days after surgery. Forty-five patients had a postoperative event, including cardiac death (3), myocardial infarction (12), unstable angina/ischemic ventricular fibrillation (2), stroke (3), or elevated troponin I, reflecting myocardial necrosis (25). Preoperative endothelium dependent FMD was significantly lower in patients with an event (4.9 $\pm 3.1 \%)$ than in those without an event (7.3 $\pm 5 \% ; P=0.001)$, whereas endothelium-independent vasodilation to nitroglycerin was similar in both groups. In a Cox proportional-hazards model, the independent predictors of events were age $(P=0.001)$, renal insufficiency $(P=0.03)$, noncarotid surgery $(P=0.05)$, and lower brachial artery FMD $(P=0.007)$. In this study, impaired brachial artery endothelial function was independently predicts postoperative cardiac events, which supports a role for endothelial dysfunction in the pathogenesis of cardiovascular disease.

The primary endpoint of this study, Schier et al. ${ }^{[76]}$ investigated whether preoperative BART-derived variables would predict postoperative complications, not restricted to cardiovascular events but inclusive of all postoperative complications that commonly occur after major thoracic surgery. The authors investigated 63 patients using BART-derived variables, including FMD, in preoperative risk stratification for major thoracic surgery. Patients in the low FMD group experienced more postoperative complications when compared high FMD: 54\% versus 30\% had one or more adverse postoperative event, and $11 \%$ versus 0 had three or more adverse postoperative events $(P<0.001)$, respectively. The authors concluded that preoperative microvascular dysfunction can be identified in patients at increased risk for postoperative complications.

\section{CONCLUSION}

The understanding of the vascular regulation of blood flow and perfusion in the peripheral circulation has grown dramatically in the past 3 decades. The endothelium plays a crucial role in regulating blood vessel function and is an important prognostic indicator of arterial function and cardiovascular risk. Alterations in arterial function are critical in the pathogenesis of cardiovascular disease including the risk factors that lead up to overt CAD and CV surgery. In addition, rehabilitation strategies in the context of 
primary and secondary prevention for CV disease (hypertension, obesity, stroke, MI) and following surgery have important positive impacts on nitric oxide and hence conduit artery endothelial function. Future focus should remain on the optimal mode and intensity of such rehabilitation strategies for the benefit of endothelial function and lowering CV risk and disease.

\section{Authors' roles \& responsibilities}

SAP Conception and design study; manuscript redaction or critical review of its content; final manuscript approval

DKA Conception and design study; manuscript redaction or critical review of its content; final manuscript approval

RGM Conception and design study; manuscript redaction or critical review of its content; final manuscript approval

FRC Conception and design study; manuscript redaction or critical review of its content; final manuscript approval

RC Conception and design study; manuscript redaction or critical review of its content; final manuscript approval

RBJ Conception and design study; manuscript redaction or critical review of its content; final manuscript approval

RA Conception and design study; manuscript redaction or critical review of its content; final manuscript approval

ABS Conception and design study; manuscript redaction or critical review of its content; final manuscript approval

\section{REFERENCES}

1. Rocha-e-Silva M. Cardiovascular effects of shock and trauma in experimental models. A review. Braz J Cardiovasc Surg. 2016;31 (1):45-51.

2. Landmesser $\mathrm{U}$, Hornig B, Drexler $\mathrm{H}$. Endothelial function: a critical determinant in atherosclerosis? Circulation. 2004;109(21 Suppl 1):II27-II33.

3. Anderson TJ, Phillips SA. Assessment and prognosis of peripheral artery measures of vascular function. Prog Cardiovasc Dis. 2015;57(5):497-509.

4. Dharmashankar K, Welsh A, Wang J, KizhakekuttuTJ, Ying R, Gutterman $D D$, et al. Nitric oxide synthase-dependent vasodilation of human subcutaneous arterioles correlates with noninvasive measurements of endothelial function. Am J Hypertens. 2012;25(5):528-34.

5. Koller A, Sun D, Huang A, Kaley G. Corelease of nitric oxide and prostaglandins mediates flow-dependent dilation of rat gracilis muscle arterioles. Am J Physiol. 1994;267(1 Pt 2):H326-32.

6. Phillips SA, Hatoum OA, Gutterman DD. The mechanism of flow-induced dilation in human adipose arterioles involves hydrogen peroxide during CAD. Am J Physiol Heart Circ Physiol. 2007;292(1):H93-100.

7. Celermajer DS, Sorensen KE, Bull C, Robinson J, Deanfield JE. Endotheliumdependent dilation in the systemic arteries of asymptomatic subjects relates to coronary risk factors and their interaction. J Am Coll Cardiol. 1994;24(6):1468-74.

8. Terata K, Miura H, Liu Y, Loberiza F, Gutterman DD. Human coronary arteriolar dilation to adrenomedullin: role of nitric oxide and $\mathrm{K}(+)$ channels. Am J Physiol Heart Circ Physiol. 2000;279(6):H2620-6.

9. Phillips SA, Mahmoud AM, Brown MD, Haus JM. Exercise interventions and peripheral arterial function: implications for cardio-metabolic disease. Prog Cardiovasc Dis. 2015;57(5):521-34.

10. Anderson TJ, Uehata A, Gerhard MD, Meredith IT, Knab S, Delagrange $D$, et al. Close relation of endothelial function in the human coronary and peripheral circulations. J Am Coll Cardiol. 1995;26(5):1235-41.

11. Anderson TJ, Meredith IT, Yeung AC, Frei B, Selwyn AP, Ganz P. The effect of cholesterol-lowering and antioxidant therapy on endotheliumdependent coronary vasomotion. N Engl J Med. 1995;332(8):488-93.

12. Celermajer DS, Sorensen KE, Spiegelhalter DJ, Georgakopoulos D, Robinson J, Deanfield JE. Aging is associated with endothelial dysfunction in healthy men years before the age-related decline in women. J Am Coll Cardiol. 1994;24(2):471-6.

13. Green DJ, Dawson EA, Groenewoud HM, Jones H, Thijssen DH. Is flowmediated dilation nitric oxide mediated? A meta-analysis. Hypertension. 2014;63(2):376-82.

14. Joannides R, Haefeli WE, Linder L, Richard V, Bakkali EH, Thuillez C, et al. Nitric oxide is responsible for flow-dependent dilatation of human peripheral conduit arteries in vivo. Circulation. 1995;91(5):1314-9.

15. Yeboah J, Crouse JR, Hsu FC, Burke GL, Herrington DM. Brachial flowmediated dilation predicts incident cardiovascular events in older adults: the Cardiovascular Health Study. Circulation. 2007;115(18):2390-7.

16. Yeboah J, Folsom AR, Burke GL, Johnson C, Polak JF, Post W, et al. Predictive value of brachial flow-mediated dilation for incident cardiovascular events in a population-based study: The multi-ethnic study of atherosclerosis. Circulation. 2009;120(6):502-9.

17. Panza JA, Quyyumi AA, Brush Jr JE, Epstein SE. Abnormal endotheliumdependent vascular relaxation in patients with essential hypertension. N Engl J Med. 1990;323(1):22-7.

18. Hokanson DE, Sumner DS, Strandness DE Jr. An electrically calibrated plethysmograph for direct measurement of limb blood flow. IEEE Trans Biomed Eng. 1975;22(1):25-9.

19. Johnstone MT, Creager SJ, Scales KM, Cusco JA, Lee BK, Creager MA. Impaired endothelium-dependent vasodilation in patients with insulindependent diabetes mellitus. Circulation. 1993;88(6):2510-6.

20. Huang AL, Silver AE, Shvenke E, Schopfer DW, Jahangir E, Titas MA, et al. Predictive value of reactive hyperemia for cardiovascular events in patients with peripheral arterial disease undergoing vascular surgery. Arterioscler Thromb Vasc Biol. 2007;27(10):2113-9.

21. Jonk AM, Houben AJ, de Jongh RT, Serne EH, Schaper NC, Stehouwer CD. Microvascular dysfunction in obesity: a potential mechanism in the pathogenesis of obesity-associated insulin resistance and hypertension. Physiology. 2007;22: 252-60.

22. Mahmoud AM, Szczurek MR, Blackburn BK, Mey JT, Chen Z, Robinson AT, et al. Hyperinsulinemia augments endothelin-1 protein expression and impairs vasodilation of human skeletal muscle arterioles. Physiol Rep. 2016;4(16):e12895.

23. Grizelj I, Cavka A, Bian JT, Szczurek M, Robinson A, Shinde S, et al. Reduced flow-and acetylcholine-induced dilations in visceral compared to subcutaneous adipose arterioles in human morbid obesity. Microcirculation. 2015;22(1):44-53.

24. De Ciuceis C, Porteri E, Rizzoni D, Corbellini C, La Boria E, Boari GE, et al. Effects of weight loss on structural and functional alterations of subcutaneous small arteries in obese patients. Hypertension. 2011;58(1):29-36.

25. Chan SY, Mancini GB, Kuramoto L, Schulzer M, Frohlich J, Ignaszewski $A$, et al. The prognostic importance of endothelial dysfunction and carotid atheroma burden in patients with coronary artery disease. J Am Coll Cardiol. 2003;42(6):1037-43.

26. Sugamata W, Nakamura T, Uematsu M, Kitta Y, Fujioka D, Saito Y, et al. Combined assessment of flow-mediated dilation of the brachial artery 
and brachial-ankle pulse wave velocity improves the prediction of future coronary events in patients with chronic coronary artery disease. J Cardiol. 2014;64(3):179-84.

27. Simova I, Denchev S. Endothelial functional and structural impairment in patients with different degrees of coronary artery disease development. Heart Vessels. 2008;23(5):308-15.

28. Kuvin JT, Patel AR, Sliney KA, Pandian NG, Rand WM, Udelson JE, et al. Peripheral vascular endothelial function testing as a noninvasive indicator of coronary artery disease. J Am Coll Cardiol. 2001;38(7):1843-9.

29. Wang X, Guo F, Li G, Cao Y, Fu H. Prognostic role of brachial reactivity in patients with ST myocardial infarction after percutaneous coronary intervention. Coron Artery Dis. 2009;20(7):467-72.

30. Kaźmierski M, Michalewska-Włudarczyk A, Krzych LJ, Tendera M. Diagnostic value of flow mediated dilatation measurement for coronary artery lesions in men under 45 years of age. Cardiol J. 2010;17(3):288-92.

31. Kaźmierski M, Michalewska-Włudarczyk A, Krzych LJ. Intima-media thickness and flow-mediated dilatation in the diagnosis of coronary artery disease in perimenopausal women. Pol Arch Med Wewn. 2010;120(5):181-8.

32. Inaba Y, Chen JA, Bergmann SR. Prediction of future cardiovascular outcomes by flow-mediated vasodilatation of brachial artery: a metaanalysis. Int J Cardiovasc Imaging. 2010;26(6):631-40.

33. Patti G, Pasceri V, Melfi R, Goffredo C, Chello M, D'Ambrosio A, et al. Impaired flow-mediated dilation and risk of restenosis in patients undergoing coronary stent implantation. Circulation. 2005;111(1):70-5.

34. Frick M, Suessenbacher A, Alber HF, Dichtl W, Ulmer H, Pachinger O, et al. Prognostic value of brachial artery endothelial function and wall thickness. J Am Coll Cardiol. 2005;46(6):1006-10.

35. Muiesan ML, Salvetti M, Paini A, Monteduro C, Galbassini G, Poisa P, et al. Prognostic role of flow-mediated dilatation of the brachial artery in hypertensive patients. J Hypertens. 2008;26(8):1612-8.

36. Meyer B, Mörtl D, Strecker K, Hülsmann M, Kulemann V, Neunteufl T, et al. Flow-mediated vasodilation predicts outcome in patients with chronic heart failure: comparison with B-type natriuretic peptide. J Am Coll Cardiol. 2005;46(6):1011-8

37. Leung FP, Yung LM, Laher I, Yao X, Chen ZY, Huang Y. Exercise, vascular wall and cardiovascular diseases: an update (Part 1). Sports Med. 2008;38(12):1009-24.

38. Higashi Y, Yoshizumi M. Exercise and endothelial function: role of endothelium-derived nitric oxide and oxidative stress in healthy subjects and hypertensive patients. Pharmacol Ther. 2004;102(1):87-96.

39. Kojda G, Hambrecht R. Molecular mechanisms of vascular adaptations to exercise. Physical activity as an effective antioxidant therapy. Cardiovasc Res. 2005;67(2):187-97.

40. Hambrecht R, Adams V, Erbs S, Linke A, Kränkel N, Shu Y, et al. Regular physical activity improves endothelial function in patients with coronary artery disease by increasing phosphorylation of endothelial nitric oxide synthase. Circulation. 2003;107(25):3152-8.

41. Maiorana A, O'Driscoll G, Cheetham C, Dembo L, Stanton K, Goodman C, et al.. The effect of combined aerobic and resistance exercise training on vascular function in type 2 diabetes. J Am Coll Cardiol. 2001;38(3):860-6.

42. Clarkson P, Montgomery HE, Mullen MJ, Donald AE, Powe AJ, Bull T, et al. Exercise training enhances endothelial function in young men. J Am Coll Cardiol. 1999;33(5):1379-85.

43. Bruning RS, Sturek M. Benefits of exercise training on coronary blood flow in coronary artery disease patients. Prog Cardiovasc Dis. 2015;57(5):443-53.

44. Hambrecht R, Wolf A, Gielen S, Linke A, Hofer J, Erbs S, et al. Effect of exercise on coronary endothelial function in patients with coronary artery disease. N Engl J Med. 2000;342(7):454-60.

45. Siasos G, Athanasiou D, Terzis G, Stasinaki A, Oikonomou E, Tsitkanou S, et al. Acute effects of different types of aerobic exercise on endothelial function and arterial stiffness. Eur J Prev Cardiol. 2016;23(14):1565-72.
46. Franklin NC, Robinson AT, Bian JT, Ali MM, Norkeviciute E, McGinty P, et al. Circuit resistance training attenuates acute exertion-induced reductions in arterial function but not inflammation in obese women. Metab Syndr Relat Disord. 2015;3(5):227-34.

47. Green DJ, Maiorana A, O'Driscoll G, Taylor R. Effect of exercise training on endothelium-derived nitric oxide function in humans. J Physiol. 2004;561(Pt 1):1-25.

48. Green DJ. Exercise training as vascular medicine: direct impacts on the vasculature in humans. Exerc Sport Sci Rev. 2009;37(4):196-202.

49. Collier SR, Kanaley JA, Carhart R Jr, Frechette V, Tobin MM, Hall AK, et al. Effect of 4 weeks of aerobic or resistance exercise training on arterial stiffness, blood flow and blood pressure in pre- and stage-1 hypertensives. J Hum Hypertens. 2008;22(10):678-86.

50. Robinson AT, Franklin NC, Norkeviciute E, Bian JT, Babana JC, Szczurek $M R$, et al. Improved arterial flow-mediated dilation after exertion involves hydrogen peroxide in overweight and obese adults following aerobic exercise training. J Hypertens. 2016;34(7):1309-16.

51. Jacomini AM, Souza HC, Dias DS, Brito JO, Pinheiro LC, Silva AB, et al. Training status as a marker of the relationship between nitric oxide, oxidative stress, and blood pressure in older adult women. Oxid Med Cell Longev. 2015;2015:8262383.

52. Brawner CA, Churilla JR, Keteyian SJ. Prevalence of physical activity is lower among individuals with chronic disease. Med Sci Sports Exerc. 2016;48(6):1062-7.

53. Schmidt W, Endres M, Dimeo F, Jungehulsing GJ. Train the vessel, gain the brain: Physical activity and vessel function and the impact on stroke prevention and outcome in cerebrovascular disease. Cerebrovasc Dis. 2013;35(4):303-12.

54. Hambrecht R, Fiehn E, Weigl C, Gielen S, Hamann C, Kaiser R, et al. Regular physical exercise corrects endothelial dysfunction and improves exercise capacity in patients with chronic heart failure. Circulation. 1998; 98:2709-15.

55. Duncker DJ, Bache RJ. Regulation of coronary blood flow during exercise. Physiol Rev. 2008;88(3):1009-86.

56. Humphreys RE, Green DJ, Cable NT, Thijssen DH, Dawson EA. Low-flow mediated constriction: the yin to FMD's yang? Expert Rev Cardiovasc Ther. 2014;12(5):557-64.

57. Bacon SL, Sherwood A, Hinderliter A, Plourde A, Pierson L, Blumenthal $J A$. The influence of endothelial function and myocardial ischemia on peak oxygen consumption in patients with coronary artery disease. Int J Vasc Med. 2012;2012:274381.

58. LukTH, Dai YL, Siu CW, Yiu KH, Chan HT, Lee SW, et al. Effect of exercise training on vascular endothelial function in patients with stable coronary artery disease: a randomized controlled trial. Eur J Prev Cardiol. 2012;19(4):830-9.

59. Kim C, Choi HE, Jung H, Kang SH, Kim JH, Byun YS. Impact of aerobic exercise training on endothelial function in acute coronary syndrome. Ann Rehabil Med. 2014;38(3):388-95.

60. Van Craenenbroeck EM, Frederix G, Pattyn N, Beckers P, Van Craenenbroeck AH, Gevaert A, et al. Effects of aerobic interval training and continuous training on cellular markers of endothelial integrity in coronary artery disease: a SAINTEX-CAD substudy. Am J Physiol Heart Circ Physiol. 2015;309(11):H1876-82.

61. Currie KD, Dubberley JB, McKelvie RS, MacDonald MJ. Low-volume, high-intensity interval training in patients with CAD. Med Sci Sports Exerc. 2013;45(8):1436-42.

62. Walsh JH, Bilsborough W, Maiorana A, Best M, O'Driscoll GJ, Taylor RR, et al. Exercise training improves conduit vessel function in patients with coronary artery disease. J Appl Physiol. 2003;95(1):20-5.

63. Harris LM, Faggioli GL, Shah R, Koerner N, Lillis L, Dandona P, et al. Vascular reactivity in patients with peripheral vascular disease. Am J Cardiol. 1995;76:207-12

64. Januszek R, Mika P, Konik A, Petriczek T, Nowobilski R, Niżankowski R. 
Effect of treadmill training on endothelial function and walking abilities in patients with peripheral arterial disease. J Cardiol. 2014;64(2):145-51. 65. Januszek R, Mika P, Nowobilski R, Maga P, Niżankowski R. The improvement of walking abilities and endothelial function after the supervised training treadmill program (STTP) in patients with peripheral artery disease (PAD) is not related to prostacyclin and thromboxane release. Int J Cardiol. 2016;222:813-8.

66. Parmenter BJ, Dieberg G, Smart NA. Exercise training for management of peripheral arterial disease: a systematic review and meta-analysis. Sports Med. 2015;45(2):231-44.

67. Santos-Garcia D, Blanco M, Serena J, Arias S, Milllán M, Rodríguez-Yáñez $M$, et al. Brachial arterial flow mediated dilation in acute ischemic stroke. Eur J Neurol. 2009;16(6):684-90.

68. Santos-Garcia D, Blanco M, Serena J, Rodríguez-Yáñez M, Leira R, Castillo J. Impaired brachial flow-mediated dilation is a predictor of a newonset vascular event after stroke. Cerebrovasc Dis. 2011;32(2):155-62.

69. Soares-Miranda L, Siscovick DS, Psaty BM, Longstreth WT, Mozaffarian D. Physical activity and risk of coronary heart disease and stroke in older adults. Circulation. 2016;133(2):147-55.

70. Sattelmair JR, Kurth T, Buring JE, Lee IMC-NP. Physical activity and risk of stroke in women. Stroke [Internet]. 2010;41:1243-50
71. Billinger SA, Mattlage AE, Ashenden AL, Lentz A, Harter G. Aerobic exercise in subacute stroke improves cardiovascular health and physical performance. J Neurol Phys Ther. 2012;36(4):159-65.

72. Takatori K, Matsumoto D, Okada Y, Nakamura J, Shomoto K. Effect of intensive rehabilitation on physical function and arterial function in community-dwelling chronic stroke survivors. Top Stroke Rehabil. 2012;19(5):377-83.

73. Verma S, Buchanan MR, Anderson TJ. Endothelial function testing as a biomarker of vascular disease. Circulation. 2003;108(17):20549.

74. Sangalli F Guazzi M, Senni S, Sala W, Caruso R, Costa MC, et al. Assessing endothelial responsiveness after cardiopulmonary bypass: insights on different perfusion modalities. J Cardiothorac Vasc Anesth. 2015;29(4):912-6.

75. Gokce N, Keaney JF Jr, Hunter LM, Watkins MT, Menzoian JO, Vita JA. Risk stratification for postoperative cardiovascular events via noninvasive assessment of endothelial function: a prospective study. Circulation. 2002;105(13):1567-72.

76. Schier R, Hinkelbein J, Marcus H, Mehran R, El-Zein R, Hofstetter W, et al. Preoperative microvascular dysfunction: a prospective, observational study expanding risk assessment strategies in major thoracic surgery. Ann Thorac Surg. 2012;94(1):226-33. 